\title{
Weatherability of Polypropylene by Accelerated Weathering Tests and Outdoor Exposure Tests in Japan
}

\author{
Kenichi Shimizu, ${ }^{1,2}$ Yuuki Tokuta, ${ }^{1,2}$ Akihiro Oishi, ${ }^{1,3}$ \\ Takashi Kuriyama, ${ }^{1,4}$ and Masao Kunioka ${ }^{1,3}$ \\ ${ }^{1}$ Polymer Subcommittee in the Industrial Technology Cooperative Promotion Committee, Umezono 1-1-1, Tsukuba, \\ Ibaraki 305-8560, Japan \\ ${ }^{2}$ Tokyo Metropolitan Industrial Technology Research Institute, Aomi 2-4-10, Koto-ku, Tokyo 135-0064, Japan \\ ${ }^{3}$ National Institute of Advanced Industrial Science and Technology (AIST), Higashi 1-1-1, Tsukuba, Ibaraki 305-8565, Japan \\ ${ }^{4}$ Yamagata University, Jonan 4-3-16, Yonezawa, Yamagata 992-8510, Japan
}

Correspondence should be addressed to Masao Kunioka; m.kunioka@aist.go.jp

Received 29 June 2016; Accepted 4 September 2016

Academic Editor: Alan K. T. Lau

Copyright (C) 2016 Kenichi Shimizu et al. This is an open access article distributed under the Creative Commons Attribution License, which permits unrestricted use, distribution, and reproduction in any medium, provided the original work is properly cited.

\begin{abstract}
As a joint study of the Polymer Subcommittee in the Industrial Technology Cooperative Promotion Committee, in which members are Japanese local governmental research institutes and National Institute of Advanced Industrial Science and Technology (AIST, Japan), carried out from 2010 to 2012, polyethylene reference sample (PE-RS) pieces and six types of polypropylene (PP) were subjected to accelerated weathering tests and outdoor exposure tests, resulting in the following findings. (1) The PE-RS was subjected to eight $100 \mathrm{~h}$ exposure tests in the same test machine. The accelerated weathering test machines of the participating institutes had high reproducibility. (2) The PE-RS CI values were greater when the temperature in the chamber was greater during accelerated weathering tests, and there was a high correlation with the average temperature in the outdoor exposure tests at 20 places in Japan. (3) By comparing the change in PP strength by normalizing the degradation environment using the PE-RS CI values, the accelerated weathering test with results showing the highest correlation with the outdoor exposure test results was the one with the xenon arc lamp at an irradiance of $60 \mathrm{~W} / \mathrm{m}^{2}$ and a BPT of $63^{\circ} \mathrm{C}$.
\end{abstract}

\section{Introduction}

Because plastics have lower specific gravities and are more easily moldable compared to metals and ceramics, their applications as device components have expanded, allowing components to become lighter and leading to cost reductions. In the future, as weight and cost reductions continue, the opportunities for plastics to be used in harsh environments will multiply. Materials used in outdoor locations are placed under harsh conditions, being exposed to sunlight and temperature changes. Therefore, evaluating the weather resistance of these materials is extremely important for their safe use. Outdoor exposure tests are the most useful for observing the changes that occur in plastics when exposed to real environmental conditions. However, currently, rapid product development is often desired, so accelerated weathering tests using accelerated weathering test machines are required.

Accelerated weathering tests are methods of exposure testing that attempt to rapidly reproduce the changes that occur in materials on outdoor exposure tests; methods include irradiation from an artificial light source and this may be accompanied by water spraying and cyclic experimental conditions, including changes in temperature, relative humidity, and irradiation energy [1-3]. Several light sources are available, including xenon arc lamps [4-6], open-flame carbon arc lamps (i.e., sunshine carbon arc lamp type) [7], ultraviolet carbon arc lamp type [8], ultraviolet fluorescent lamp type [9], and metal halide lamp type [10]. Furthermore, specifications have been stipulated concerning the test machines or test methods for all of these types of light sources 


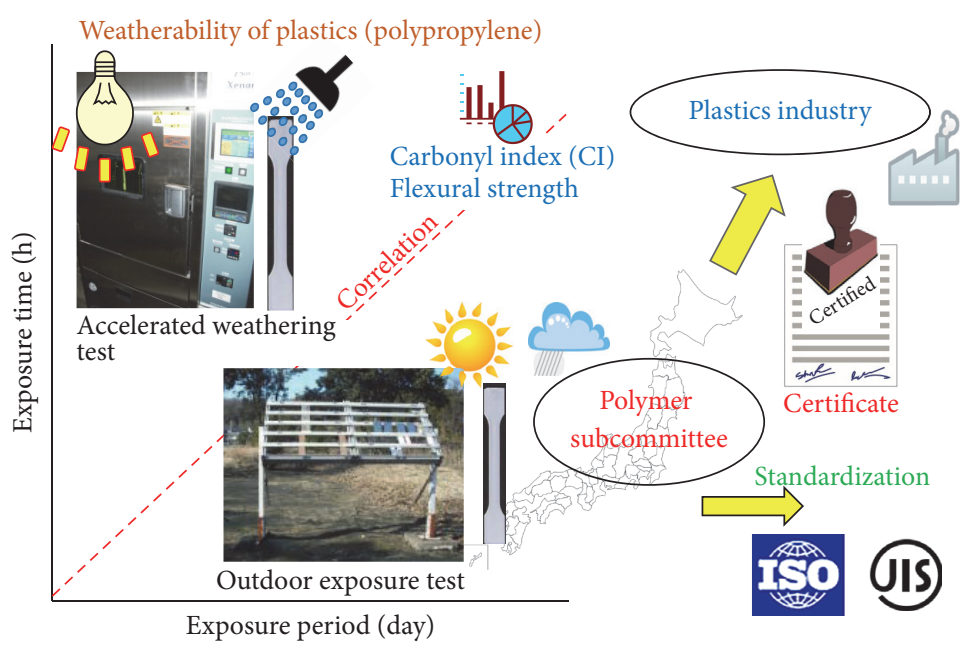

Figure 1: Aims of joint study in Polymer Subcommittee.

other than metal halide lamps. Each type of lamp has a characteristic spectral irradiance that affects the degradation of polymer materials differently. In Japan, the open-flame carbon arc lamp type is commonly used, but at present the xenon arc lamp type, the ISO standard, is also used widely [11]. In addition, xenon arc lamps with high light intensities have been developed in recent years and are used in some tests.

When selecting an appropriate accelerated testing method based on the International Standard (ISO) 4892-1 [12] (same as the Japan Industrial Standard (JIS) K73501), reproducibility for confirming the quality of required properties of different batches, acceleration degree for confirming the satisfying required property, and correlation between outdoor exposure and weathering test machine for confirming the lifetime outdoors for plastic product are very important. Many data of weathering test for adhesives and other outdoor applications were published [13-15]. Thus, the objective of this joint study was to perform accelerated weathering testing and outdoor exposure testing of a polyethylene reference sample (PE-RS) [16-19] and six types of polypropylene (PP) at public research organizations under the Polymer Subcommittee in the Industrial Technology Cooperative Promotion Committee (Japan) to obtain findings regarding the reproducibility and acceleration of the accelerated weathering testing and the correlation between the accelerated weathering testing and outdoor exposure testing as indicated in Figure 1.

The Polymer Subcommittee was founded about 50 years ago under the Industrial Technology Cooperative Promotion Committee to develop the technical level of participating members (41 research institutes) including local governmental research institutes, public research organizations, and National Institute of Advanced Industrial Science and Technology (AIST, Japan), for polymer product characterization by information exchange and cooperative research projects. A variety of accelerated weathering test machines have been introduced in the public research organizations under the Polymer Subcommittee in the Industrial Technology Cooperative Promotion Committee (Japan) as indicated in Figure 2, and these range widely in operating conditions. Using the accelerated weathering test machines already in operation in these public research organizations is advantageous because exposure test data can be obtained from a variety of test machines and test conditions in a relatively short time.

\section{Materials and Methods}

\subsection{Test Pieces}

2.1.1. Polyethylene Reference Sample (PE-RS). Test pieces purchased from the Japan Weathering Test Center (JWTC) were used without alteration. Figure 3 shows the outward appearance of the PE-RS $(45 \times 15 \times 0.2 \mathrm{~mm})$ mounted in a plastic flame of slide folder.

2.1.2. Polypropylene (PP). Six types of pellets supplied from Sumitomo Chemical Co., Ltd., were formed into multipurpose test pieces as indicated in JIS K7139 (2009) which is modified from ISO 20753 (2008) [20], via injection molding at Yamagata University before being used. Sample test pieces (Type A1, parallel part: $80 \mathrm{~mm}$; thickness: $4 \mathrm{~mm}$ ) were used as indicated in Figure 3(b). Table 1 indicates the attributes of the PP types used. Melt flow rates (MFR) of PP were measured by Melt Indexer (Toyo Seiki Seisaku-sho Ltd., Japan) at $230^{\circ} \mathrm{C}$ and $2.16 \mathrm{~kg}$ [21]. Melting temperature and heat of fusion were measured by DSC-60 (Shimadzu Co., Japan) at increasing rate of $10^{\circ} \mathrm{C} / \mathrm{min}[22]$. Test specimens were prepared using a 55-ton injection machine (J55E-C3, Japan Steel Works Co.). The mold had dumbbell-shaped cavity with $10 \mathrm{~mm}$ width, $4 \mathrm{~mm}$ thickness, and $159 \mathrm{~mm}$ length. The barrel temperature of PP homopolymer and copolymer was set from 190 to $210^{\circ} \mathrm{C}$ and 170 to $200^{\circ} \mathrm{C}$, respectively, with same mold temperature of $40^{\circ} \mathrm{C}$. 


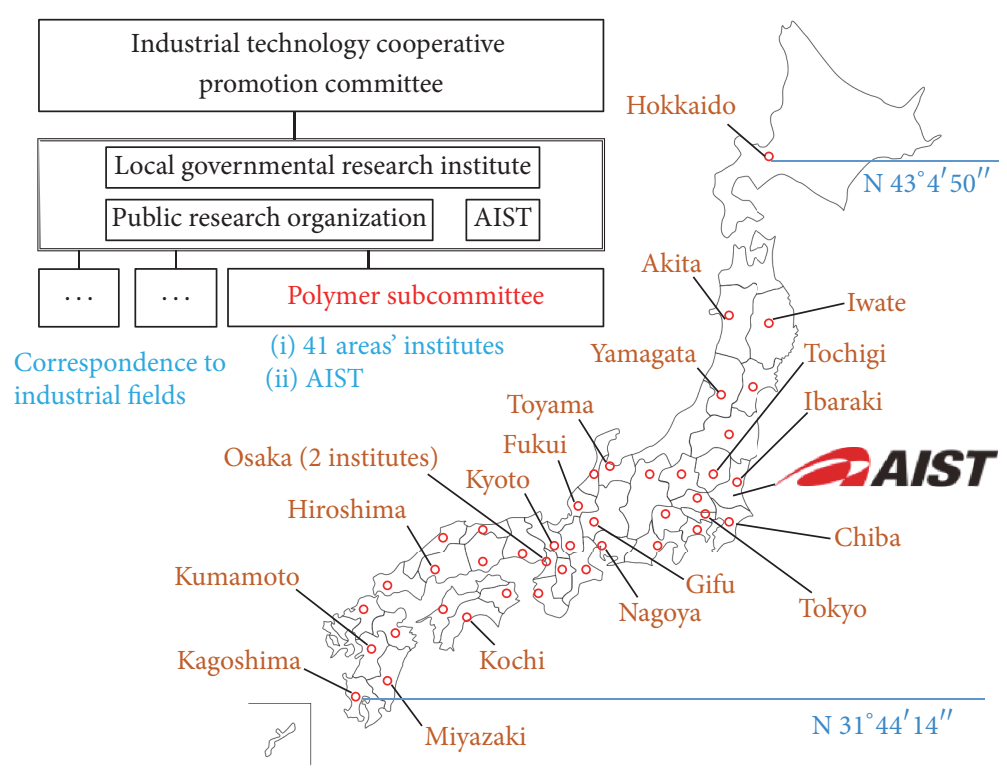

Figure 2: Participation members (o) of Polymer Subcommittee in Industrial Technology Cooperative Promotion Committee. Participation members of outdoor exposure test in Table 3 are located at indicated place names. AIST is National Institute of Advanced Industrial Science and Technology.

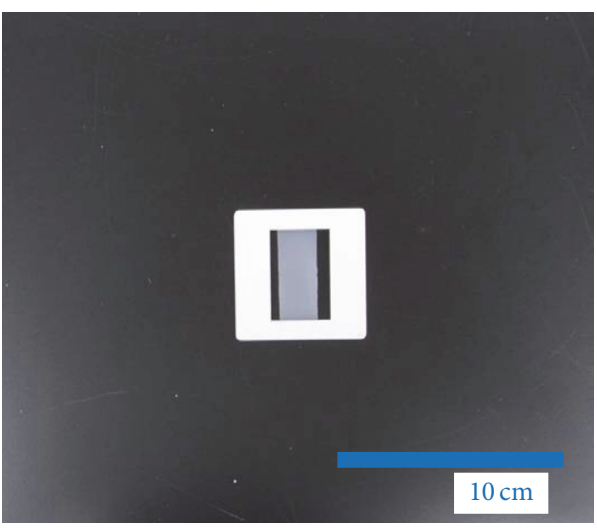

(a)

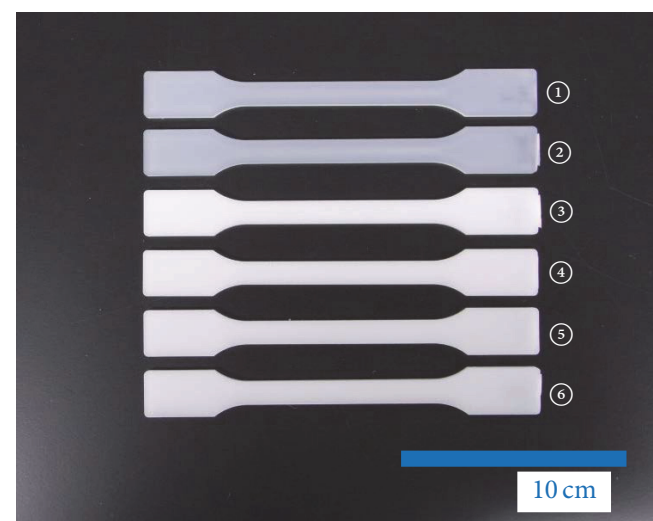

(b)

FIGURE 3: Polyethylene reference sample (PE-RS) (a) and polypropylene (PP) homopolymer and PP copolymer samples (b) as indicated in Table 1.

TABLE 1: Attributes of polypropylene (PP) used in weathering experiments.

\begin{tabular}{|c|c|c|c|c|c|}
\hline Code & Molecular structure & Additive formulation & $\mathrm{MFR}^{\mathrm{c}}, \mathrm{g} / 10 \mathrm{~min}$ & Melting temperature, ${ }^{\circ} \mathrm{C}$ & Heat of fusion, $\mathrm{J} / \mathrm{g}$ \\
\hline (1) & PP homopolymer & Standard $^{\mathrm{a}}$ & 7.4 & 166 & 122 \\
\hline (2) & PP homopolymer & Weather resistant ${ }^{\mathrm{b}}$ & 7.1 & 167 & 112 \\
\hline (3) & PP copolymer & Standard ${ }^{\mathrm{a}}$ & 3.3 & 166 & 94 \\
\hline (4) & PP copolymer & Weather resistant $\mathrm{t}^{\mathrm{b}}$ & 3.4 & 166 & 105 \\
\hline (5) & PP copolymer & Standard $^{\mathrm{a}}$ & 8.5 & 167 & 100 \\
\hline (6) & PP copolymer & Weather resistant ${ }^{\mathrm{b}}$ & 8.8 & 167 & 101 \\
\hline
\end{tabular}

${ }^{\mathrm{a}}$ Antioxidant was melt-mixed.

${ }^{\mathrm{b}}$ Antioxidant and light stabilizer were melt-mixed.

${ }^{\mathrm{c}}$ Melt flow rate (MFR) was measured at $230^{\circ} \mathrm{C}$ and $2.16 \mathrm{~kg}$. 
TABLE 2: Exposure conditions for 100-hour accelerated weathering tests.

\begin{tabular}{|c|c|c|c|c|}
\hline Number & $\begin{array}{l}\text { Irradiance/(wavelengths) } \\
\left(\mathrm{W} / \mathrm{m}^{2} /(\mathrm{nm})\right)\end{array}$ & $\begin{array}{c}\mathrm{BPT}^{\mathrm{a}} \text { or } \mathrm{BST}^{\mathrm{b}} \\
\left({ }^{\circ} \mathrm{C}\right)\end{array}$ & $\begin{array}{c}\text { Chamber temperature } \\
\left({ }^{\circ} \mathrm{C}\right)\end{array}$ & $\begin{array}{l}\text { Water spray time per total irradiation } \\
\qquad(\min /(\min ))\end{array}$ \\
\hline 1 & $30 /(300-400)$ & $63 \pm 3^{a}$ & 38 & - \\
\hline 2 & $50 /(300-400)$ & $63 \pm 2^{\mathrm{a}}$ & 38 & - \\
\hline 3 & $60 /(300-700)$ & $65 \pm 2$ & 38 & - \\
\hline 4 & $60 /(300-400)$ & $65 \pm 2^{\mathrm{b}}$ & 38 & $18 /(120)$ \\
\hline 5 & $60 /(300-400)$ & $63 \pm 2^{\mathrm{a}}$ & 38 & $18 /(120)$ \\
\hline 6 & $60 /(300-400)$ & $63 \pm 3^{\mathrm{a}}$ & 38 & $18 /(120)$ \\
\hline 7 & $60 /(300-400)$ & $63 \pm 3^{\mathrm{a}}$ & 38 & $18 /(120)$ \\
\hline 8 & $60 /(300-400)$ & $63 \pm 3^{a}$ & 42 & $18 /(120)$ \\
\hline 9 & $60 /(300-400)$ & $65 \pm 2^{\mathrm{a}}$ & 52.8 & - \\
\hline 10 & $60 /(300-400)$ & $63 \pm 2^{\mathrm{a}}$ & $52-53$ & - \\
\hline 11 & $390 /(300-700)$ & $63 \pm 3^{\mathrm{a}}$ & 42 & $12 /(60)$ \\
\hline 12 & $390 /(300-700)$ & $63 \pm 3^{\mathrm{a}}$ & 38 & $18 /(120)$ \\
\hline 13 & $100 /(300-400)$ & $65 \pm 2^{\mathrm{b}}$ & 38 & $18 /(120)$ \\
\hline 14 & $100 /(300-400)$ & $65 \pm 2^{b}$ & 38 & $18 /(120)$ \\
\hline 15 & $100 /(300-400)$ & $65 \pm 2^{\mathrm{b}}$ & 38 & $18 /(120)$ \\
\hline 16 & $100 /(300-400)$ & $63 \pm 2^{\mathrm{a}}$ & 43 & \\
\hline 17 & $180 /(300-400)$ & $63^{\mathrm{a}}$ & 21 & \\
\hline 18 & $180 /(300-400)$ & $63 \pm 3^{\mathrm{a}}$ & 28 & $18 /(120)$ \\
\hline 19 & $180 /(300-400)$ & $63^{\mathrm{a}}$ & 28 & $2 /(300)$ \\
\hline 20 & $180 /(300-400)$ & $63 \pm 3^{\mathrm{a}}$ & - & $18 /(120)$ \\
\hline 21 & $180 /(300-400)$ & $63 \pm 3^{\mathrm{a}}$ & 33 & $18 /(120)$ \\
\hline 22 & $180 /(300-400)$ & $63 \pm 1^{\mathrm{a}}$ & 38 & $18 /(120)$ \\
\hline 23 & $180 /(300-400)$ & $83 \pm 2^{\mathrm{a}}$ & 41 & \\
\hline 24 & $255 /(300-700)$ & $63 \pm 3$ & 40 & $18 /(120)$ \\
\hline 25 & $255 /(300-700)$ & $63 \pm 3^{\mathrm{a}}$ & 42 & $18 /(120)$ \\
\hline 26 & $255 /(300-700)$ & $63 \pm 3^{\mathrm{a}}$ & 42 & $18 /(120)$ \\
\hline 27 & $255 /(300-700)$ & $63 \pm 3^{\mathrm{a}}$ & 43 & $18 /(120)$ \\
\hline 28 & $500 /(300-700)$ & $63 \pm 3$ & 40 & - \\
\hline 29 & $500 /(300-700)$ & $63 \pm 3$ & 40.6 & - \\
\hline 30 & $563 /(300-700)$ & $63 \pm 3$ & 38 & - \\
\hline 31 & $1000 /(300-400)$ & & 63 & - \\
\hline 32 & & - & 40 & - \\
\hline
\end{tabular}

BST: black standard thermometer temperature. BPT: black panel thermometer temperature.

\subsection{Exposure Tests}

2.2.1. $100 \mathrm{~h}$ Accelerated Weathering Test. The PE-RS samples were sent to the 20 institutions listed in Appendix A, and exposure tests were conducted for 100 hours in 31 accelerated weathering test machines owned by these institutions. Also, as a control, PE-RS was exposed for $100 \mathrm{~h}$ in a thermostatic chamber set to $40^{\circ} \mathrm{C}$. The main exposure conditions of the accelerated weathering test machines are indicated in Table 2. The accelerated weathering test machines included 21 xenon arc lamp machines for numbers one to 23 (23 samples), four open-flame carbon arc lamp type machines for numbers 24 to 27 , three ultraviolet carbon arc lamp type machines for numbers 28 to 30 , and one metal halide lamp type machine for number 31. The exposure conditions and handling of periods when the test machines were halted were determined by the participating institutions according to circumstances.
All institutes calibrate the intensity of illumination using certified illuminometer once a year and black panel temperature (BPT) using black panel thermometer continuously during weathering tests.

2.2.2. $800 \mathrm{~h}$ Accelerated Weathering Test. Samples of PERS and three types of PP were sent to the 10 institutions listed in Appendix B, and exposure tests were conducted for $800 \mathrm{~h}$ within the accelerated weathering test machines owned by these institutions. The main exposure conditions of the accelerated weathering test machines are listed in Table 3. Each PE-RS was exposed for $100 \mathrm{~h}$, while the PP samples were removed for five tests, respectively, after 100, 200, 300, 500 , and $800 \mathrm{~h}$ had elapsed. The exposure conditions and handling of periods when the test machines were halted were determined by the participating institutions according to 


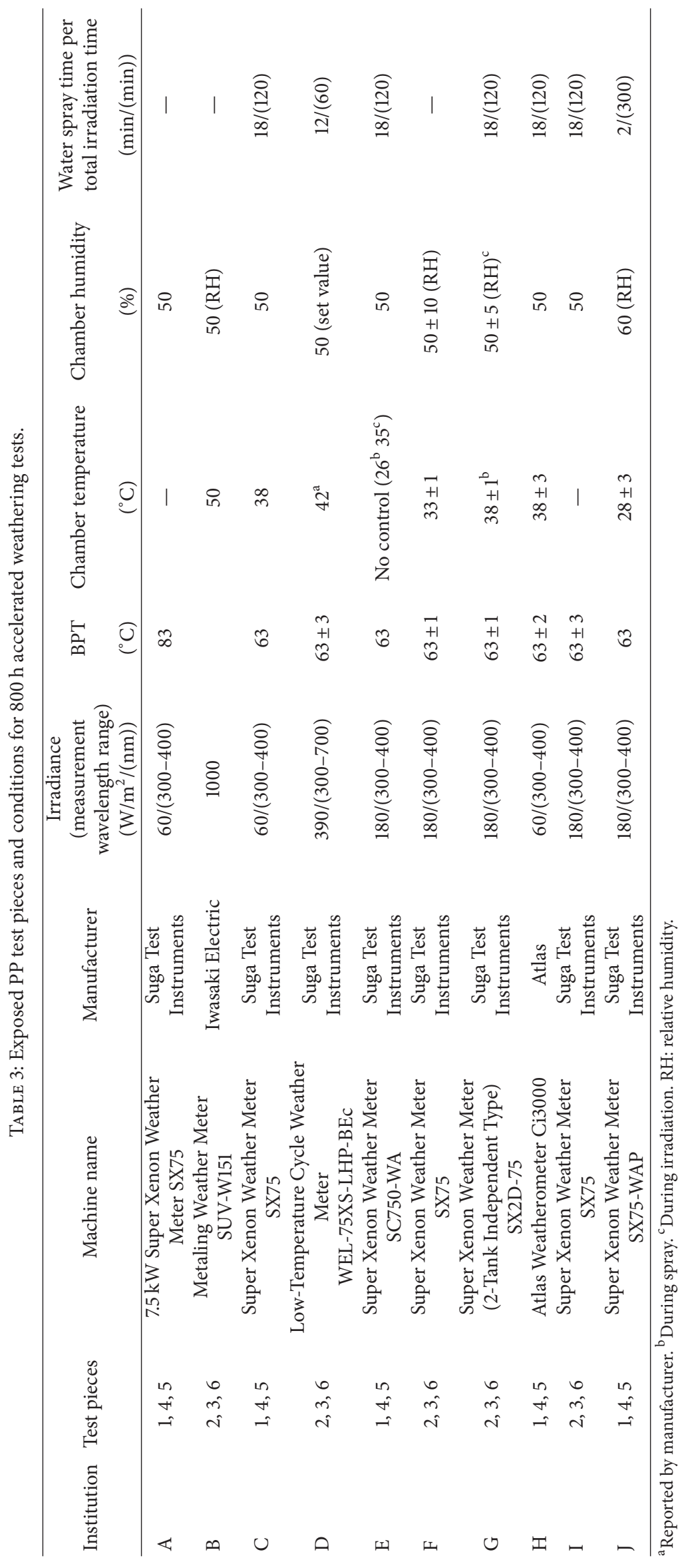


TABLE 4: Features of lamps for weathering test machine.

\begin{tabular}{|c|c|c|c|}
\hline Lamp type & Mechanism & $\begin{array}{l}\text { Characteristic of spectral } \\
\text { distribution }\end{array}$ & Standard ${ }^{\text {a }}$ related to plastics \\
\hline Xenon arc & $\begin{array}{l}\text { Light by passing electricity } \\
\text { through ionized Xenon gas in } \\
\text { glass tube }\end{array}$ & $\begin{array}{l}\text { Extremely resembling sunlight in } \\
\text { UV and visible part }\end{array}$ & $\begin{array}{l}\text { ISO 4892-2 (same as JIS } \\
\text { K7350-2) [23] }\end{array}$ \\
\hline Open flame carbon arc & Carbon arc in open air & $\begin{array}{l}\text { Resembling sunlight UV-B } \\
(280-315 \mathrm{~nm}) \text { and severalfold } \\
\text { intensity in UV-A (315-400 nm) }\end{array}$ & $\begin{array}{l}\text { ISO 4892-4 (same as JIS } \\
\text { K7350-4) [24] }\end{array}$ \\
\hline Ultraviolet carbon arc & Carbon arc in glass tube & $\begin{array}{l}\text { Major peak at } 388 \mathrm{~nm} \text {, minor } \\
\text { peaks at } 358 \text { and } 415 \mathrm{~nm}\end{array}$ & JIS B7751 [25], ASTM D5031 [26] \\
\hline Metal halide lamp & $\begin{array}{l}\text { Light by passing electricity } \\
\text { through ionized mercury and } \\
\text { metal halide gases in quartz glass } \\
\text { tube }\end{array}$ & $\begin{array}{l}20-30 \text { times UV }(270-450 \mathrm{~nm}) \\
\text { as compared to sunlight }\end{array}$ & None \\
\hline
\end{tabular}

${ }^{a}$ ISO: International Standard, JIS: Japan Industrial Standard, and ASTM: American Society for Testing and Materials.

circumstances. Features of lamps for weathering test machine are indicated in Table 4.

2.2.3. Outdoors Exposure Test. Samples of PE-RS and three types of PP were sent to the 20 institutions listed in Appendix C, and exposure tests were conducted for two years on exposure platforms owned by these institutions. The exposed test pieces and main exposure conditions at each institution are indicated in Table 5. Each PE-RS was exposed for one month, while the PP samples were removed for five tests, respectively, after 3, 6, 9, 12, and 24 months had elapsed.

\subsection{Degradation Measurement}

2.3.1. Carbonyl Index (CI). The methods described in the specification [16-19] were followed. Specifically, a Fourier transform infrared spectrometer (FTIR, Thermo Scientific Nicolet-6700) was used to measure the infrared absorption spectrum of the postexposure PE-RS sample films (thickness $0.2 \mathrm{~mm}$ ) in the range from $2200 \mathrm{~cm}^{-1}$ to $1600 \mathrm{~cm}^{-1}$ on transmission mode at a typical average of 24 scans, and the CI was calculated from the absorbances at around $1715 \mathrm{~cm}^{-1}$ (peak of carboxyl group produced by oxodegradation) and $2020 \mathrm{~cm}^{-1}$ (peak of methylene group (standard)), according to

$$
\mathrm{CI}=\frac{A_{1715}}{A_{2020}}
$$

Here, $A_{1715}$ and $A_{2020}$ indicate the absorbances of the peaks around 1715 and $2020 \mathrm{~cm}^{-1}$, respectively.

2.3.2. Observation of Surface Texture. The central area of parallel part of as-mold and postexposure PP test pieces was observed by a scanning-white-light interferometer (Zygo, New View 6200). It was used at $20 \pm 1^{\circ} \mathrm{C}$. A $50 x$ objective lens was used with a $0.5 \mathrm{x}$ zoom lens; the horizontal resolution was $0.88 \mu \mathrm{m}$, and the $z$-axis scan length was $150 \mu \mathrm{m}$.

2.3.3. Flexural Strength. To calculate the flexural strength (maximum value) of the PP test pieces before and after exposure, a micrometer and a universal testing machine (Autograph AG-10TD) were used; the measurements followed the ISO 178 (same as JIS-K7171 (2008)) [27] protocol. Triplicated samples were measured at by three points bending with $64 \mathrm{~mm}$ lower span gap and $2 \mathrm{~mm} / \mathrm{min}$ head insertion speed. The postexposure PP test pieces were placed in the test machine so that the exposed surface was the surface under tension.

2.3.4. Weather Data Acquisition. The relevant dates and closest observation points to the locations of the institutions performing the exposure were selected from data provided by the Japan Meteorological Agency, which is publically available on the Internet [28]. Monthly average temperature, precipitation, and insolation time data were acquired for the period from September 2011 to August 2013.

\section{Results and Discussion}

The carbonyl index (CI) quantitatively represents the combined effects of temperature and UV rays on the samples. PE-RS, supplied by JWTC, was standardized with respect to the material, production method, outward appearance, dimensions, absorbance ratio to measure $\mathrm{CI}$ in an outdoor exposure test, and an experimental light source exposure test. The CI of PE-RS increases linearly with increasing exposure time in a uniform exposure environment and increases with temperature.

Figure 4 shows the CI of the PE-RS sample exposed for $100 \mathrm{~h}$ in accelerated weathering test machines. The numbers on the horizontal axis match those in Table 2. Comparing the CI of samples under different exposure conditions, the $\mathrm{CI}$ was greater when exposed in the accelerated weathering test machines (numbers 1-31) compared to when exposed in a thermostatic chamber at $40^{\circ} \mathrm{C}(\mathrm{NO} .32)$, confirming that $\mathrm{CI}$ of PE-RS increases due to the combined effects of temperature and light irradiation. Meanwhile, sample numbers 10, 23, and 31 had larger CI values, and these were exposed to either higher temperatures in the chamber or higher black panel temperatures, confirming that the $\mathrm{CI}$ of the PE-RS is 


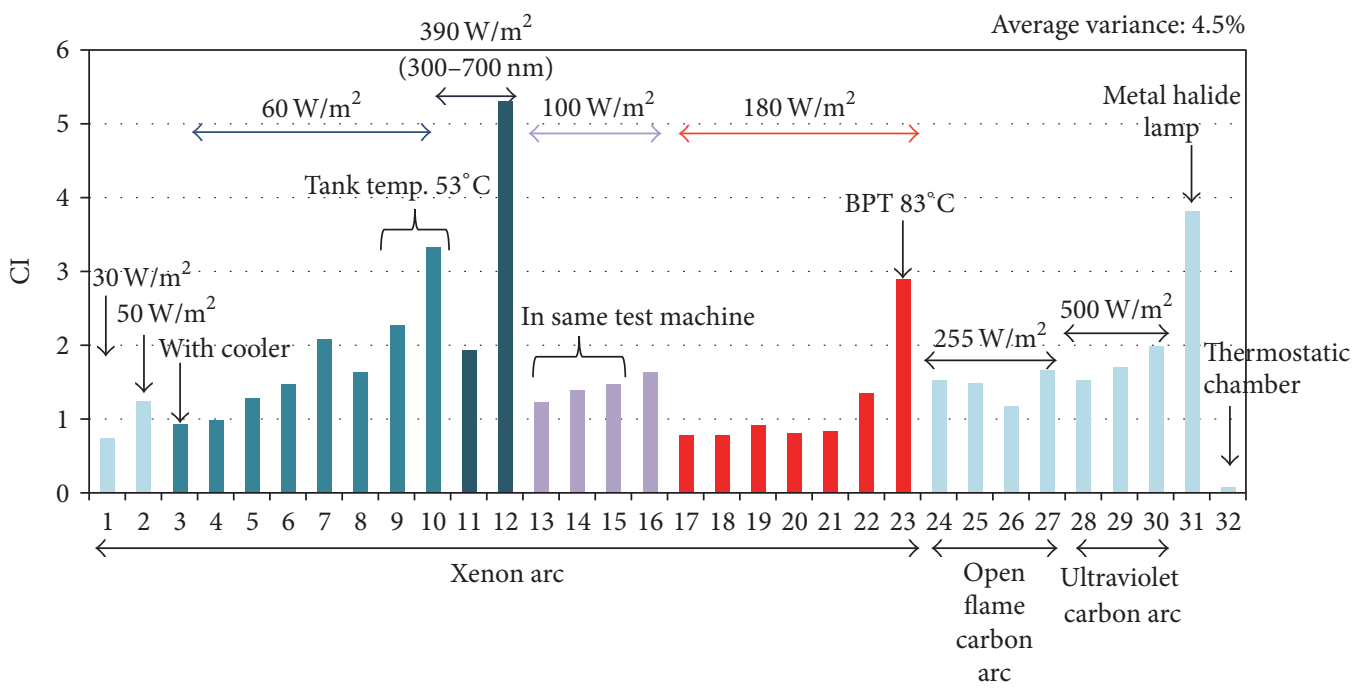

FIgURE 4: Carbonyl index (CI) of PE-RS exposed for $100 \mathrm{~h}$ in an accelerated weathering machine.

TABLE 5: Outdoor exposed PP test pieces at place (latitude and longitude) with conditions for outdoor exposure tests.

\begin{tabular}{|c|c|c|c|c|c|}
\hline Institution & Latitude & Longitude & Test pieces & Compass bearing & Elevation $^{\mathrm{a}}$ \\
\hline Hokkaido & $\mathrm{N} 43^{\circ} 4^{\prime} 50^{\prime \prime}$ & $\mathrm{E} 141^{\circ} 20^{\prime} 15^{\prime \prime}$ & (1), (4), (5) & South & $\mathrm{C}$ \\
\hline Akita Prefecture & $\mathrm{N} 39^{\circ} 43^{\prime}$ & $\mathrm{E} 140^{\circ} 6^{\prime}$ & (1), (4), (5) & South & B \\
\hline Iwate Prefecture & $\mathrm{N} 39^{\circ} 40^{\prime} 29^{\prime \prime}$ & $\mathrm{E} 141^{\circ} 7^{\prime} 55^{\prime \prime}$ & (2), (3), (6) & South & C \\
\hline Yamagata Prefecture & $\mathrm{N} 38^{\circ} 14^{\prime}$ & $\mathrm{E} 140^{\circ} 17^{\prime}$ & (2), (3), (6) & South & $\mathrm{C}$ \\
\hline Toyama Prefecture & $\mathrm{N} 36^{\circ} 36^{\prime} 34^{\prime \prime}$ & E1 $36^{\circ} 54^{\prime} 56^{\prime \prime}$ & (1), (4), (5) & South & C \\
\hline Tochigi Prefecture & $\mathrm{N} 36^{\circ} 19^{\prime} 8^{\prime \prime}$ & $\mathrm{E} 139^{\circ} 34^{\prime} 14^{\prime \prime}$ & (1), (4), (5) & South & A \\
\hline Ibaraki Prefecture & $\mathrm{N} 36^{\circ} 16^{\prime} 42^{\prime \prime}$ & $\mathrm{E} 139^{\circ} 53^{\prime} 4^{\prime \prime}$ & (2), (3), (6) & - & - \\
\hline Fukui Prefecture & $\mathrm{N} 36^{\circ} 7^{\prime} 0^{\prime \prime}$ & $\mathrm{E} 136^{\circ} 12^{\prime} 10^{\prime \prime}$ & (2), (3), (6) & South & A $\left(26^{\circ}\right)$ \\
\hline Tokyo & $\mathrm{N} 35^{\circ} 37^{\prime} 6^{\prime \prime}$ & $\mathrm{E} 139^{\circ} 46^{\prime} 46^{\prime \prime}$ & (2), (3), (6) & South & $\mathrm{C}$ \\
\hline Chiba Prefecture & $\mathrm{N} 35^{\circ} 36^{\prime} 45^{\prime \prime}$ & $\mathrm{E} 140^{\circ} 9^{\prime} 5^{\prime \prime}$ & (1), (4), (5) & South & C \\
\hline Gifu Prefecture & $\mathrm{N} 35^{\circ} 21^{\prime} 5^{\prime \prime}$ & E136 $44^{\prime} 33^{\prime \prime}$ & (1), (4), (5) & South & $\mathrm{E}\left(90^{\circ}\right)$ \\
\hline Nagoya City & $\mathrm{N} 35^{\circ} 7^{\prime} 10^{\prime \prime}$ & E136 $53^{\prime} 20^{\prime \prime}$ & (2), (3), (6) & South & $\mathrm{A}\left(25^{\circ}\right)$ \\
\hline Kyoto City & $\mathrm{N} 34^{\circ} 59^{\prime} 32^{\prime \prime}$ & $\mathrm{E} 135^{\circ} 44^{\prime} 41^{\prime \prime}$ & (1), (4), (5) & South & E \\
\hline JCII (Osaka) & $\mathrm{N} 34^{\circ} 40^{\prime} 13^{\prime \prime}$ & $\mathrm{E} 135^{\circ} 34^{\prime} 12^{\prime \prime}$ & (2), (3), (6) & - & - \\
\hline Osaka Prefecture & $\mathrm{N} 34^{\circ} 26^{\prime} 37^{\prime \prime}$ & $\mathrm{E} 135^{\circ} 26^{\prime} 41^{\prime \prime}$ & (1), (4), (5) & South & B \\
\hline Hiroshima Prefecture & $\mathrm{N} 34^{\circ} 13^{\prime} 38^{\prime \prime}$ & $\mathrm{E} 132^{\circ} 35^{\prime} 10^{\prime \prime}$ & (2), (3), (6) & South & $\mathrm{D}\left(5^{\circ}\right)$ \\
\hline Kochi Prefecture & $\mathrm{N} 33^{\circ} 34^{\prime} 23^{\prime \prime}$ & $\mathrm{E} 133^{\circ} 34^{\prime} 44^{\prime \prime}$ & (2), (3), (6) & South & C \\
\hline Kumamoto Prefecture & $\mathrm{N} 32^{\circ} 47^{\prime} 5^{\prime \prime}$ & $\mathrm{E} 130^{\circ} 46^{\prime} 1^{\prime \prime}$ & (2), (3), (6) & - & - \\
\hline Miyazaki Prefecture & $\mathrm{N} 32^{\circ} 2^{\prime} 15^{\prime \prime}$ & $\mathrm{E} 131^{\circ} 15^{\prime} 19^{\prime \prime}$ & (1), (4), (5) & South & $\mathrm{A}\left(22^{\circ}\right)$ \\
\hline Kagoshima Prefecture & $\mathrm{N} 31^{\circ} 44^{\prime} 14^{\prime \prime}$ & $\mathrm{E} 130^{\circ} 42^{\prime} 54^{\prime \prime}$ & (1), (4), (5) & South & $\mathrm{C}$ \\
\hline
\end{tabular}

${ }^{a}$ Elevation: A; Latitude $-10^{\circ}, \mathrm{B} ; 30^{\circ}, \mathrm{C} ; 45^{\circ}, \mathrm{D} ; 5-10^{\circ}$, E; other.

strongly affected by temperature. In a comparison between experimental conditions, the open-flame carbon arc and ultraviolet carbon arc lamps resulted in nearly equivalent CI values; these correspond to the $60-100 \mathrm{~W} / \mathrm{m}^{2}$ range with the xenon arc lamp type. Notably, the xenon arc lamp at $180 \mathrm{~W} / \mathrm{m}^{2}$ and a black panel thermometer temperature (BPT) of $63^{\circ} \mathrm{C}$ (numbers 17-22) resulted in smaller $\mathrm{CI}$ values than at an irradiance of $60 \mathrm{~W} / \mathrm{m}^{2}$ and a BPT of $63^{\circ} \mathrm{C}$ (numbers $3-10$ ). We believe that this is because the PE-RS samples as indicated in Figure 3 were white, resulting in lower visible light absorbance compared to the black panel. In addition, the temperature of the accelerated weathering test machine chambers was controlled until the BPT became a specific temperature during light irradiation at fixed irradiance, leading to the temperature in the chamber being maintained at a lower level compared to the high irradiance conditions and resulting in the PE-RS temperature being lower in the case of irradiation at $180 \mathrm{~W} / \mathrm{m}^{2}$ than that at $60 \mathrm{~W} / \mathrm{m}^{2}$.

Additionally, during irradiation at $60 \mathrm{~W} / \mathrm{m}^{2}$ and BPT $63^{\circ} \mathrm{C}$ (numbers $3-10$ ) and at $180 \mathrm{~W} / \mathrm{m}^{2}$ and BPT $63^{\circ} \mathrm{C}$ with a xenon arc lamp, the CI differed by up to a factor of two, despite the exposure conditions being very similar. However, aside 


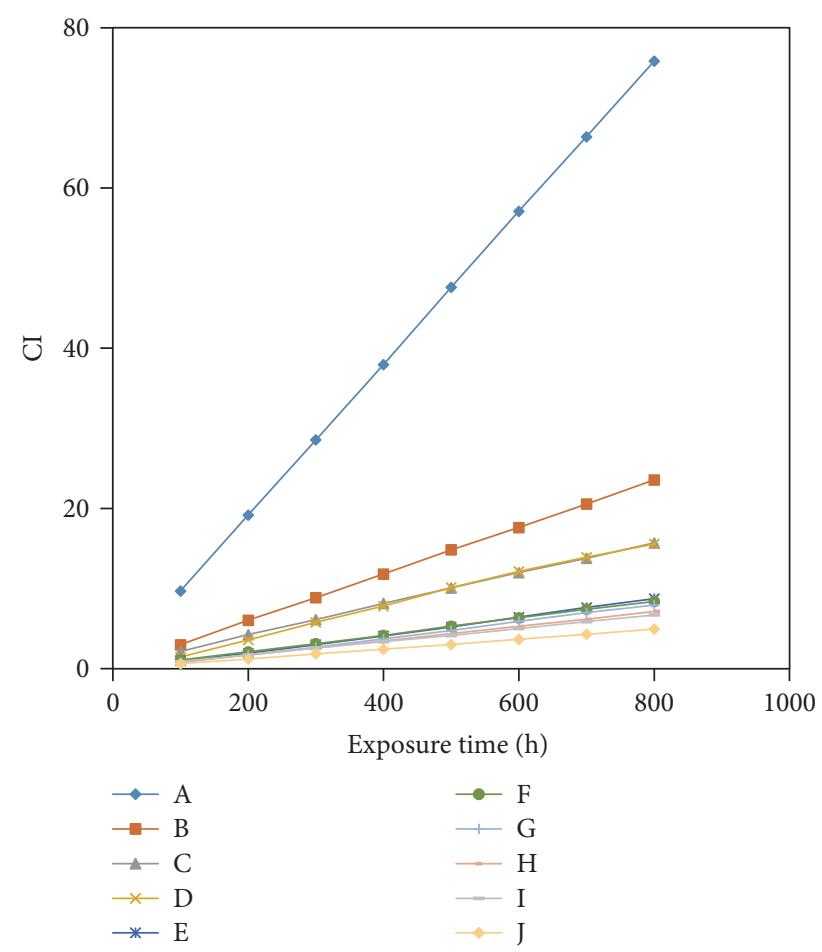

FIGURE 5: Cumulative CI values for PE-RS during eight repetitions of $100 \mathrm{~h}$ exposure in an accelerated weathering test machine. A-J are institution codes (detailed machine condition) as indicated in Table 3.

from these conditions, there were no significant differences between samples within the same test machines (see samples 13,14 , and 15). Also, for sample 12, the CI value was large; however, it was determined that, for this test, exposure time may have been longer than originally suggested.

Figure 5 shows the cumulative CI values for PE-RS during eight repeated 100-hour exposures. The CI values increased proportionally with exposure time in all of the exposure test machines, with a correlation coefficient of at least 0.999 in each case. This indicates that the exposure test machines produced highly reproducible data. The greatest and smallest cumulative CI values for the PE-RS samples after 800 hours of exposure were 8.74 and 4.94 for the five institutions using a xenon arc lamp type at $180 \mathrm{~W} / \mathrm{m}^{2}$ and a BPT of $63^{\circ} \mathrm{C}$, respectively, and 15.70 and 7.15 for the three institutions using a xenon arc lamp type at $60 \mathrm{~W} / \mathrm{m}^{2}$ and a $\mathrm{BPT}$ of $63^{\circ} \mathrm{C}$, respectively. In common with the $100 \mathrm{~h}$ exposure tests, there was a maximum twofold difference between machines. In addition, the average values were, respectively, $7.34\left(180 \mathrm{~W} / \mathrm{m}^{2}\right)$ and $12.80\left(60 \mathrm{~W} / \mathrm{m}^{2}\right)$.

Figure 6 shows the relationship between PP flexural strength and exposure time obtained from accelerated weathering tests. PP flexural strength rose in the initial stages of exposure, but under each set of exposure conditions, once flexural strength began to decrease, it decreased monotonically with increasing exposure time. Bending tests are believed to be an appropriate test to evaluate the degree of PP degradation; however, when evaluating degradation using strength tests, the relationship between exposure time and a decrease in strength is not always monotonic in other polymers.

Figure 7 shows a representative example of surface texture changes in a PP sample exposed in an accelerated weathering test machine. As is evident from Figure 7, the most prominent change in surface texture on exposure was cracking in the direction perpendicular to the flow direction, and the number of cracks increased with increasing exposure time. In general, cracks concentrate stress, leading to brittle fracturing. Consequently, the fracture strength value ceases to be stable. However, once numerous cracks have developed, the cracks open during bending tests, easing the concentration of tensile strain at the tips of the individual cracks and, thus, increasing bending, leading to a more ductile stress-strain curve. In fact, the postexposure test samples rarely suffered from brittle failure in the elastic region during bending tests. In addition, the opening of numerous cracks dissipates strain energy, decreasing the test force. Thus, changes in surface texture can be inferred to be intimately involved in the result of a monotonically decreasing flexural strength.

However, changes in flexural strength during initial degradation are low, and so detecting early degradation is difficult. As a result of verifying the bending strength values and the surface texture, the strength decrease started at an exposure time of approximately $200-500 \mathrm{~h}$ for the standardformulation PP (samples(1), (3), and (5)), and the only sample that started to decrease in flexural strength at $100 \mathrm{~h}$ was sample (5) from exposure institution A, in which cracks had clearly developed (see Figure 7). In contrast, for the weatherresistant PP formulations (2), (4), and (6)), a decrease in the bending test only arose under the high irradiance conditions of a xenon arc lamp type at $180 \mathrm{~W} / \mathrm{m}^{2}$ and the metal halide lamp accelerated weathering test machines; there was no decrease in flexural strength after $800 \mathrm{~h}$ under $60 \mathrm{~W} / \mathrm{m}^{2}$ conditions, even at the high temperature (BPT conditions of $\left.83^{\circ} \mathrm{C}\right)$.

Figure 8 indicates the two-year cumulative $\mathrm{CI}$ values and locations of the exposure institutions from the test exposing PE-RS outdoors monthly for two years. However, this excludes data from institutions at which the PE-RS was lost for some reason (e.g., as a result of a storm) resulting in less than two years' worth of CI data. The greatest twoyear cumulative CI value was 29.76, measured in Kumamoto. The lowest value was 19.09 in Hokkaido. In addition, the average value at the 16 institutions that obtained two years' worth of data was 24.01. In a simple comparison of these values and the results of the $800 \mathrm{~h}$ accelerated weathering test, the exposure conditions in the accelerated weathering test machine resulting in a PE-RS CI value equivalent to that after one year of outdoor exposure were a xenon arc lamp type at $180 \mathrm{~W} / \mathrm{m}^{2}$ and a BPT of $63^{\circ} \mathrm{C}$ for $1309 \mathrm{~h}$ or $60 \mathrm{~W} / \mathrm{m}^{2}$ and a BPT of $63^{\circ} \mathrm{C}$ for $750 \mathrm{~h}$.

Figure 9 shows an example of the relationship between the number of exposure days and the cumulative CI value. The PE-RS CI exhibited periodicity by increasing greatly from spring (April) through summer (August) and a reduced rate of increase from fall (September) through winter (March); 

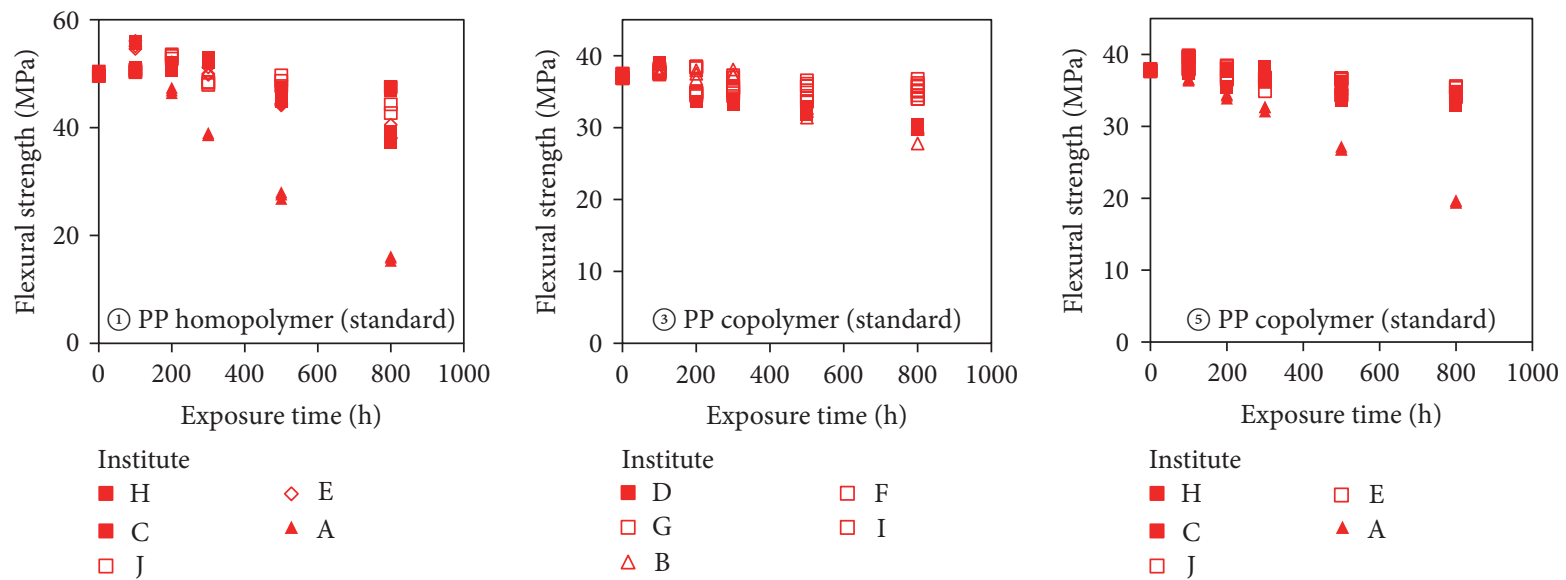

Institute

$\begin{array}{ll}\square \mathrm{D} & \square \mathrm{F} \\ \square \mathrm{G} & \square \mathrm{I} \\ \triangle \mathrm{B} & \end{array}$
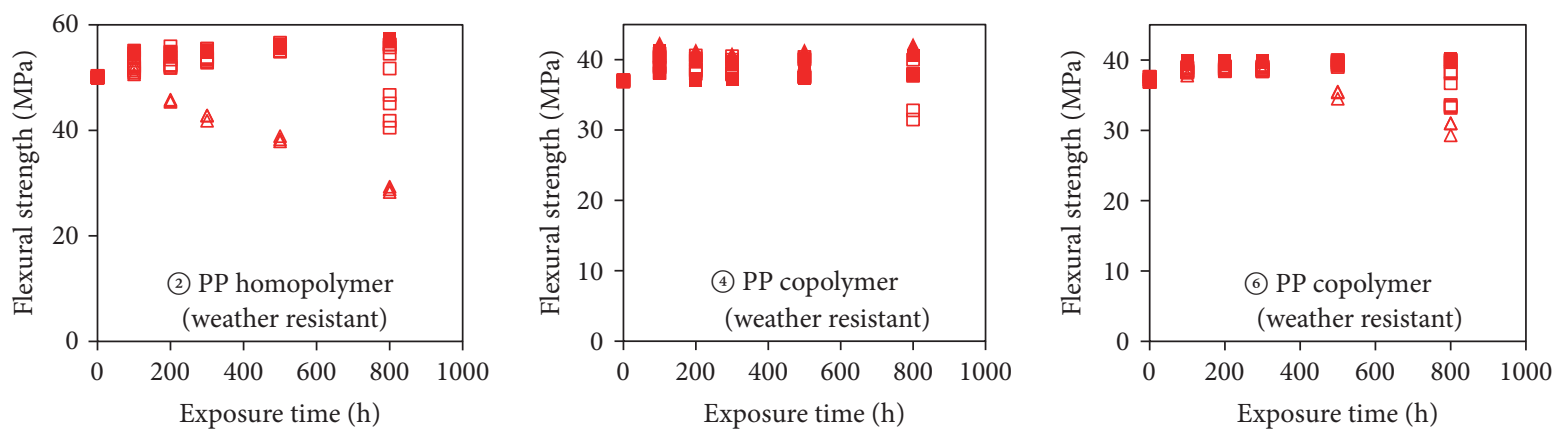

$\begin{array}{ll}\text { Institute } & \\ \square \mathrm{D} & \square \mathrm{F} \\ \square \mathrm{G} & \square \mathrm{I} \\ \triangle \mathrm{B} & \end{array}$

$\begin{array}{ll}\text { Institute } & \\ \square \mathrm{H} & \square \mathrm{E} \\ \square \mathrm{C} & \triangle \mathrm{A} \\ \square \mathrm{J} & \end{array}$

FIGURE 6: Relationship between PP flexural strength and exposure time in accelerated weathering test machine. (1)-(6) are sample codes as indicated in Table 1. A-J are institution codes as indicated in Table 3. $\mathrm{m}$ : xenon $60 \mathrm{~W}$ and $63^{\circ} \mathrm{C}$ or parity condition, $\square$ : xenon $180 \mathrm{~W}$ and $63^{\circ} \mathrm{C}$, $\Delta$ : xenon $60 \mathrm{~W}$ and $83^{\circ} \mathrm{C}$, and $\triangle$ : metal halide lamp.
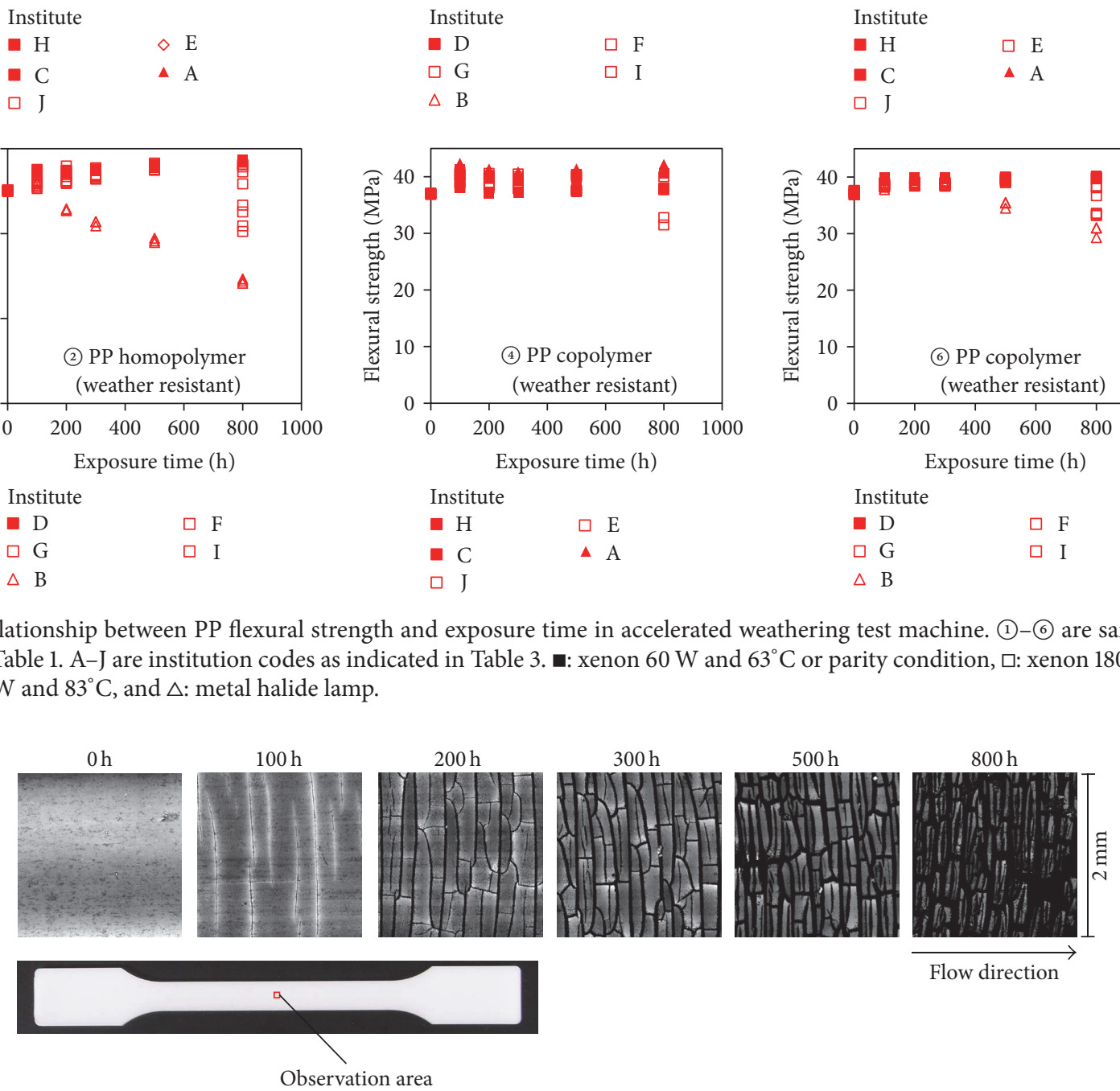

Figure 7: Surface texture changes in PP exposed to accelerated weathering test machine (institution A as indicated in Table 3, test piece code (5) as indicated in Table 1).

however, at the same time, the CI increased monotonically with increasing exposure time. Additionally, Figure 10 shows the relationship between each weather factor and two years of cumulative CI values. The correlation coefficients between the PE-RS CI value during the outdoor exposure test and the average temperature, cumulative precipitation, and cumulative insolation time were $0.712,0.217$, and 0.241 , respectively. Thus, average temperature had the highest correlation coefficient among the three weather factors. This trend matches the results of a Polymer Subcommittee joint study conducted from 2002 to 2004 [29]. This confirmed that the CI value for PE-RS CI is strongly affected by temperature.

Figure 11 shows the relationship between PP flexural strength and outdoor exposure time. The flexural strength of PP with the weather-resistant formulations (samples (2), (4), and (6) in Figure 11) did not decrease during the 24month period. In contrast, the standard-formulation PP flexural strength rose for six months and then decreased after 


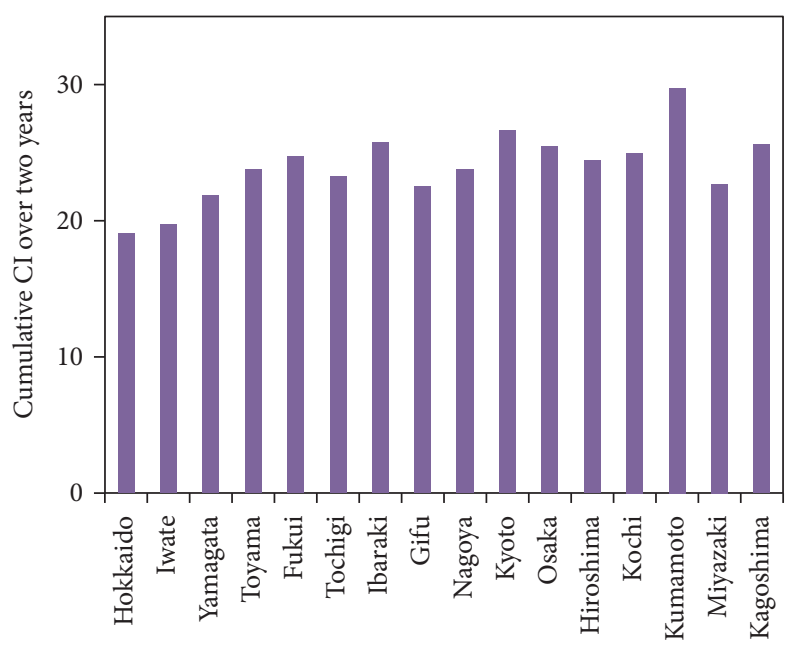

Figure 8: Cumulative PE-RS CI values at locations of exposure institutions as indicated in Table 5.

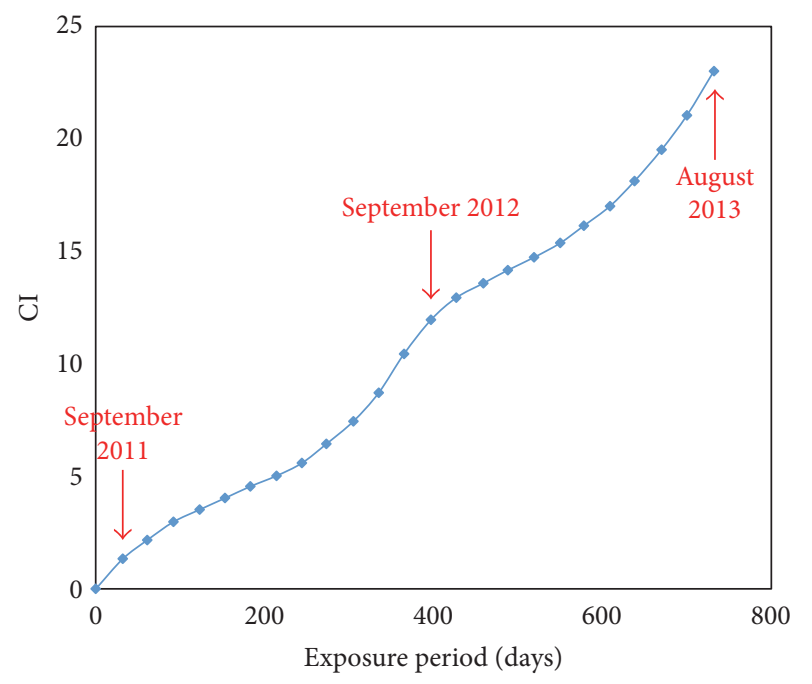

FIgUre 9: Example of cumulative PE-RS CI value and outdoor exposure (days) in Tochigi Prefecture.

nine months of exposure for a subset of samples and after twelve months of exposure for all samples, further decreasing after 24 months. The average tendency can be said to be an increase in flexural strength during the initial stage of exposure, followed by a monotonic decline with increased exposure time once decrease begins. This tendency matches the results of exposure in the accelerated weathering test machines. Nevertheless, the bending tests of the samples exposed for nine months, when the decline in flexural strength begins, resulted in a relatively large number of samples that underwent brittle failure; consequently, flexural strength was widely scattered. This tendency is not seen due to exposure in accelerated weathering test machines. One factor behind this result is believed to be the concentrated stress at the few crack tips developing during the initial stages and the cracks deeper in outdoor exposure tests compared to in accelerated weathering testing machines.
It is showed by FTIR analysis for successive microtomed PP specimen after 12-month outdoor exposure test and $400 \mathrm{~h}$ accelerated weathering test that the CI depth profiles are different from each other and the CI from 40 to $200 \mu \mathrm{m}$ depth is larger in outdoor exposure tests compared to in accelerated weathering testing [30].

Figure 12 illustrates the changes in PP flexural strength due to outdoor exposure testing and accelerated weathering testing based on the PE-RS CI values. The CI is an index that represents the combined effect of temperature and ultraviolet rays on the degradation of plastic. Using the CI, it is possible to compare changes in PP flexural strength in different exposure environments. In the outdoor exposure testing of standard-formulation PP (samples (1), (3), and (5) shown in Figure 12), the flexural strength began to decrease at a CI of around 6 to 8 , after which point there tended to be a monotonic decrease with increasing CI. In the accelerated weathering testing, due to insufficient plot points at the large CI region, it was somewhat difficult to identify a tendency towards a lower flexural strength with respect to CI under different conditions. Still, as shown for sample (1) in Figure 12, the rate of decrease in flexural strength with respect to CI can be arranged into three lines. Namely, these are the lines corresponding to the xenon arc lamp type at $180 \mathrm{~W} / \mathrm{m}^{2}$ and a $\mathrm{BPT}$ of $63^{\circ} \mathrm{C}$, at which the rate of decrease in flexural strength with respect to $\mathrm{CI}$ was the greatest; the line corresponding to the xenon arc lamp type at $60 \mathrm{~W} / \mathrm{m}^{2}$ and a BPT of $83^{\circ} \mathrm{C}$, at which the rate of decrease was the smallest; and the line corresponding to the xenon arc lamp type at $60 \mathrm{~W} / \mathrm{m}^{2}$ and a $\mathrm{BPT}$ of $63^{\circ} \mathrm{C}$, at which the rate of decrease was intermediate to above. It is even more difficult to identify a decreasing trend for samples (3) and (5) in Figure 12, but if there is another line corresponding to the metal halide lamp type in addition to the three decreasing trends stated above, the PP flexural strength in the region of large CI due to outdoor exposure testing appears to be on a line at the outside of the line corresponding to the xenon arc lamp type at $60 \mathrm{~W} / \mathrm{m}^{2}$ and a BPT of $63^{\circ} \mathrm{C}$, and among the accelerated weathering tests in this joint study, these conditions can be considered to have the highest correlation with the outdoor exposure tests. However, there was the difference that, under the conditions of accelerated weathering tests, the flexural strength decrease began at a lower CI than the outdoor exposure testing.

In the outdoor exposure tests of PP with the weatherresistant formulation (2), (4), and (6) in Figure 12), the flexural strength did not decrease, although the CI value reached approximately 30 due to two years of outdoor exposure and 75 due to $800 \mathrm{~h}$ accelerated weathering test of the xenon arc lamp type at $60 \mathrm{~W} / \mathrm{m}^{2}$ and a BPT of $83^{\circ} \mathrm{C}$ (not plotted in the figure). Meanwhile, we confirmed a drop in flexural strength at a CI of no greater than 10 under $1000 \mathrm{~W} / \mathrm{m}^{2}$ conditions using the metal halide lamp and $180 \mathrm{~W} / \mathrm{m}^{2}$ conditions using the xenon arc lamp type weathering machines. Consequently, accelerated weathering tests with high irradiance are superior in terms of rapidly obtaining a pass/fail determination for the weather-resistant formulations, but they correlated poorly with outdoor exposure testing compared to the accelerated weathering testing using a xenon arc lamp at $60 \mathrm{~W} / \mathrm{m}^{2}$. 

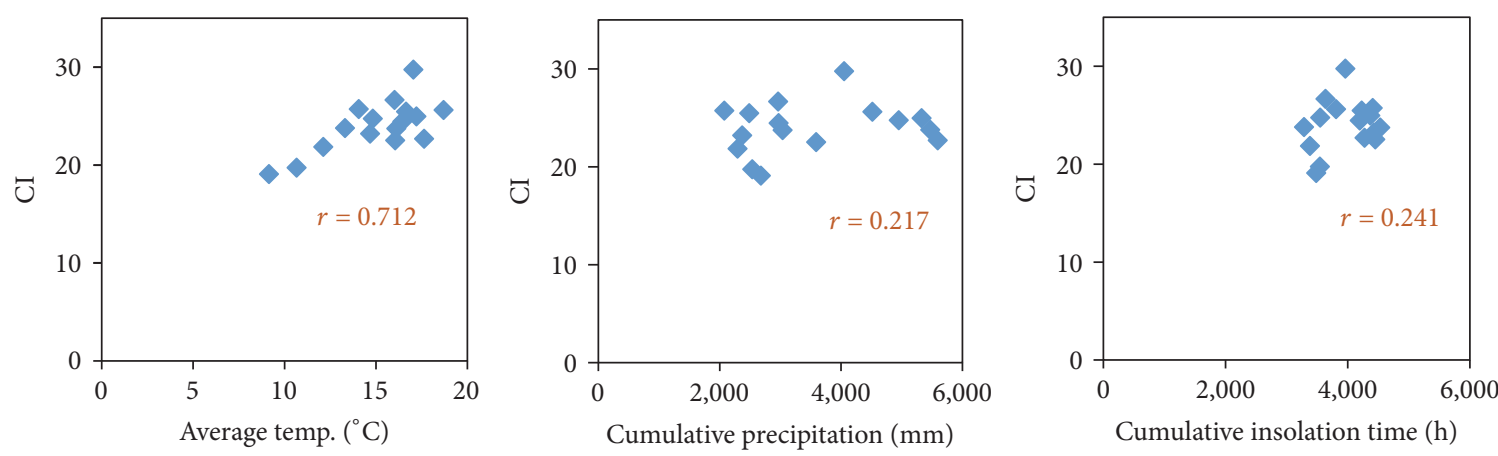

FIGURE 10: Relationship between weather factors and CI.
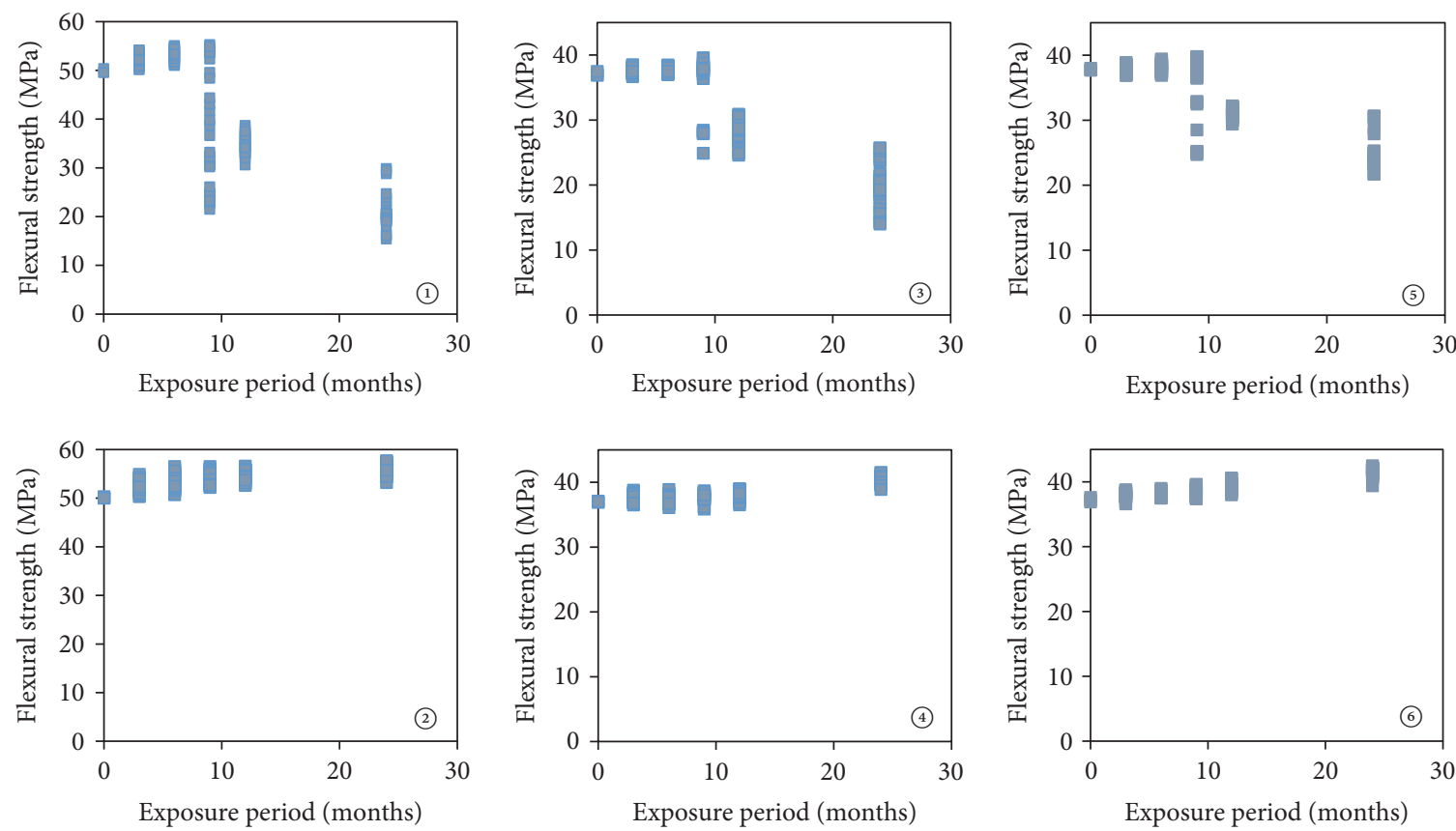

FIGURE 11: Relationship between outdoor exposure period and PP flexural strength. (1)-(6) are sample codes as indicated in Table 1.3-10 square plots looks bar by lapping.

\section{Conclusions}

In this joint study of the Polymer Subcommittee from 2010 to 2012, accelerated weathering tests and outdoor exposure tests were performed on polyethylene reference samples (PE$\mathrm{RS})$ and six types of polypropylene (PP). (1) In case of reproducibility, PE-RS was subjected to eight $100 \mathrm{~h}$ exposure tests in the same test machine. Consequently, from the measured carbonyl index (CI) of the PE-RS sample, the correlation factor between the CI value and the exposure time was found to be 0.999 , indicative of the high reproducibility of measurements carried out in the accelerated weathering test machines. (2) In case of acceleration, the PE-RS CI values were greater when the temperature in the chamber was greater during accelerated weathering tests, and there was a high correlation with the average temperature in the outdoor exposure tests. From these results, the effect of temperature on the PE-RS CI values was confirmed to be relatively large.
Due to this property, the PE-RS CI values were greater when using a xenon arc lamp with a power density of $60 \mathrm{~W} / \mathrm{m}^{2}$ than that with a $180 \mathrm{~W} / \mathrm{m}^{2}$ power density. In contrast, in both the $800 \mathrm{~h}$ accelerated weathering test and the two-year outdoor exposure test, weather-resistant PP decreased in strength on exposure to $1000 \mathrm{~W} / \mathrm{m}^{2}$ and $180 \mathrm{~W} / \mathrm{m}^{2}$ irradiation, indicating that high-energy light irradiation was effective for screening the weather-resistant formulations. (3) In case of correlation, comparing the PE-RS CI values during the outdoor exposure tests and during the accelerated weathering tests showed that the exposure time in the accelerated exposure tests resulting in a PE-RS CI value equivalent to one year of outdoor exposure was $750 \mathrm{~h}$ at an irradiance of $60 \mathrm{~W} / \mathrm{m}^{2}$ with a black panel thermometer temperature (BPT) of $63^{\circ} \mathrm{C}$, and it was $1309 \mathrm{~h}$ at an irradiance of $180 \mathrm{~W} / \mathrm{m}^{2}$ with a BPT of $63^{\circ} \mathrm{C}$. By comparing the change in PP strength by normalizing the degradation environment using the PE-RS CI values, the accelerated weathering test with results showing the highest 

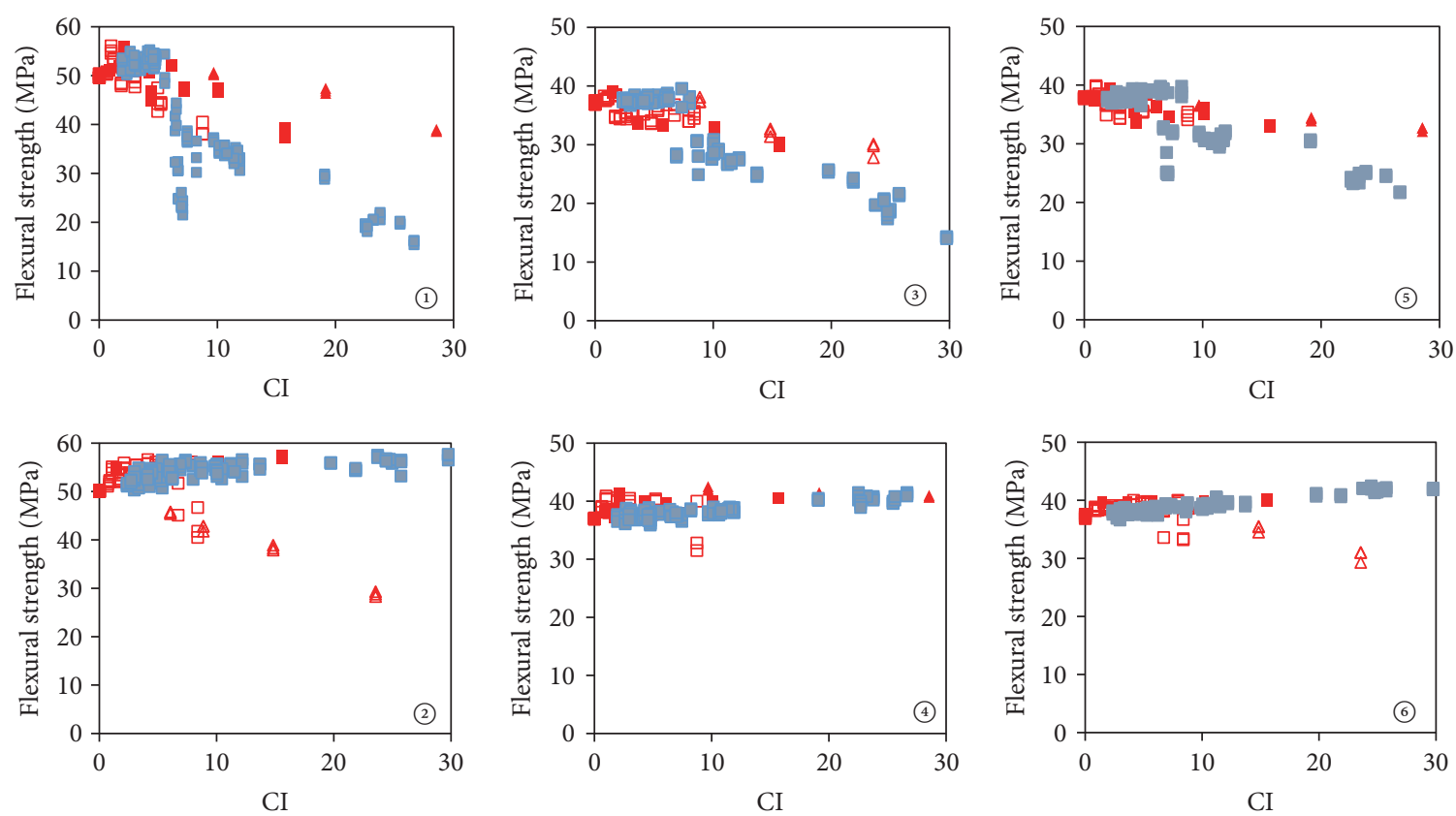

Figure 12: Changes in PP flexural strength resulting from outdoor exposure test and accelerated weathering test machines on the basis of

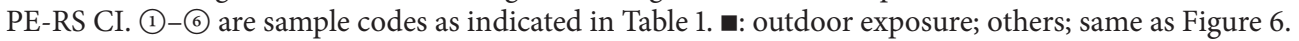

correlation with the outdoor exposure test results was the one with the xenon arc lamp at an irradiance of $60 \mathrm{~W} / \mathrm{m}^{2}$ and a $\mathrm{BPT}$ of $63^{\circ} \mathrm{C}$. The flexural strength was decreased with the surface defects of the standard-formulation PP due to the molecular weight decreasing of PP with the increase of the CI.

\section{Appendix}

\section{A. Institutions Participating in $100 \mathrm{~h}$ Accelerated Weathering Tests}

(i) Industrial Research Institute of Shizuoka Prefecture

(ii) Yamagata Research Institute of Technology

(iii) Toyama Industrial Technology Center, Human Life Technology Research Institute

(iv) Mie Prefecture Industrial Research Institute

(v) Kanagawa Industrial Technology Center

(vi) Kochi Prefectural Industrial Technology Center

(vii) Kyoto Municipal Institute of Industrial Technology and Culture

(viii) Technology Research Institute of Osaka Prefecture

(ix) Industrial Research Center of Shiga Prefecture

(x) Industrial Technology Center of Okayama Prefecture

(xi) Northeastern Industrial Research Center of Shiga Prefecture

(xii) Chiba Industrial Technology Research Institute

(xiii) Iwate Industrial Research Institute (xiv) Osaka Municipal Technical Research Institute

(xv) Industrial Technology Institute of Ibaraki Prefecture, Textile Technology Office

(xvi) Hokkaido Research Organization (HRO), Industrial Technology Research Department, Industrial Research Institute

(xvii) Industrial Technology Center of Tochigi Prefecture, Southern District Technology Support Center

(xviii) National Institute of Advanced Industrial Science and Technology, Research Institute for Innovation in Sustainable Chemistry

(xix) Japan Chemical Innovation and Inspection Institute (JCII), Highpolymer Test \& Evaluation Center, Osaka Office

(xx) Tokyo Metropolitan Industrial Technology Research Institute (11 machines)

\section{B. Institutions Participating in 800-Hour Accelerated Weathering Tests}

(i) Yamagata Research Institute of Technology

(ii) Industrial Technology Center of Okayama Prefecture

(iii) Toyama Industrial Technology Center, Human Life Technology Research Institute

(iv) Kyoto Municipal Institute of Industrial Technology and Culture

(v) Technology Research Institute of Osaka Prefecture

(vi) Chiba Industrial Technology Research Institute

(vii) Osaka Municipal Technical Research Institute 
(viii) Hokkaido Research Organization (HRO), Industrial Technology Research Department, Industrial Research Institute

(ix) National Institute of Advanced Industrial Science and Technology, Research Institute for Innovation in Sustainable Chemistry

(x) Japan Chemical Innovation and Inspection Institute (JCII), Highpolymer Test \& Evaluation Center, Osaka Office

(xi) Tokyo Metropolitan Industrial Technology Research Institute

\section{Institutions Participating in Outdoor Exposure Tests}

(i) Akita Industrial Technology Center

(ii) Hokkaido Research Organization (HRO), Industrial Technology Research Department Industrial Research Institute

(iii) Industrial Technology Center of Tochigi Prefecture, Southern District Technology Support Center

(iv) Hiroshima Prefectural Technology Research Institute, Western Region Industrial Research Center

(v) Japan Chemical Innovation and Inspection Institute (JCII), Highpolymer Test \& Evaluation Center, Osaka Office

(vi) Toyama Industrial Technology Center, Human Life Technology Research Institute

(vii) Industrial Technology Institute of Ibaraki Prefecture, Textile Technology Office

(viii) Tokyo Metropolitan Industrial Technology Research Institute

(ix) Iwate Industrial Research Institute (local incorporated administrative agency)

(x) Technology Research Institute of Osaka Prefecture

(xi) Chiba Industrial Technology Research Institute

(xii) Kagoshima Prefectural Institute of Industrial Technology

(xiii) Kumamoto Industrial Research Institute

(xiv) Industrial Technology Center, Gifu Prefectural Government

(xv) Industrial Technology Center of Fukui Prefecture

(xvi) Miyazaki Prefecture Industrial Technology Center

(xvii) Kochi Prefectural Industrial Technology Center

(xviii) Kyoto Municipal Institute of Industrial Technology and Culture

(xix) Yamagata Research Institute of Technology

(xx) Nagoya Municipal Industrial Research Institute

\section{Competing Interests}

The authors declare no conflict of interests.

\section{Acknowledgments}

This joint study was performed using a program to support the advancement of technology of the Industrial Technology Cooperative Promotion Committee (Japan) with AIST from 2010 to 2012. The authors thank Sumitomo Chemical Co., Ltd., for providing the materials for this joint study.

\section{References}

[1] Outdoor Exposure Test Handbook, Japan Weathering Test Center, 2009, http://www.jwtc.or.jp/gijutsu/01.pdf.

[2] L. F. E. Jacques, "Accelerated and outdoor/natural exposure testing of coatings," Progress in Polymer Science, vol. 25, no. 9, pp. 1337-1362, 2000.

[3] S. Brunner, P. Richner, U. Müller, and O. Guseva, "Accelerated weathering device for service life prediction for organic coatings," Polymer Testing, vol. 24, no. 1, pp. 25-31, 2005.

[4] L. E. Pimentel Real, A. M. Ferraria, and A. M. B. D. Rego, "The influence of weathering conditions on the properties of poly(vinyl chloride) for outdoor applications. An analytical study using surface analysis techniques," Polymer Testing, vol. 26, no. 1, pp. 77-87, 2007.

[5] H. Hagihara, A. Oishi, M. Funabashi, M. Kunioka, and H. Suda, "Free-volume hole size evaluated by positron annihilation lifetime spectroscopy in the amorphous part of poly(ethylene terephthalate) degraded by a weathering test," Polymer Degradation and Stability, vol. 110, pp. 389-394, 2014.

[6] M. Funabashi, F. Ninomiya, A. Oishi et al., "Highly accelerated aging method for poly(ethylene terephthalate) film using xenon lamp with heating system," Journal of Polymers, vol. 2016, Article ID 8547524, 9 pages, 2016.

[7] F. Mori, M. Koyama, and Y. Oki, "Studies on photodegradation of poly(vinyl chloride) (part 1)," Die Angewandte Makromolekulare Chemie, vol. 64, no. 1, pp. 89-99, 1977.

[8] M. Tsukada, H. Shiozaki, and J. S. Crighton, “The preparation of poly[ $N$ (n-butoxymethyl) methacrylamide] grafted silk fibers by polymerization using a low $\mathrm{pH}$ system," Journal of Applied Polymer Science, vol. 48, no. 8, pp. 1409-1416, 1993.

[9] M. Morreale, N. T. Dintcheva, and F. P. L. Mantia, "Accelerated weathering of PP based nanocomposites: effect of the presence of maleic anhydryde grafted polypropylene," eXPRESS Polymer Letters, vol. 7, no. 8, pp. 703-715, 2013.

[10] Y. Azuma, H. Takeda, S. Watanabe, and H. Nakatani, "Outdoor and accelerated weathering tests for polypropylene and polypropylene/talc composites: a comparative study of their weathering behavior," Polymer Degradation and Stability, vol. 94, no. 12, pp. 2267-2274, 2009.

[11] S. Iida, H. Takayanagi, and M. Yabe, "Introduction to accelerated weathering test methods," Research on Coatings, vol. 145, pp. 22-37, 2006.

[12] "Plastics-Methods of Exposure to Laboratory Light Sources, Part 1: General Guidance," ISO 4892-1, ISO, Geneva, Switzerland, 2016.

[13] D. Feldman, "Polymer weathering: photo-oxidation," Journal of Polymers and the Environment, vol. 10, no. 4, pp. 163-173, 2002.

[14] L. A. Escobar and W. Q. Meeker, "A review of accelerated test models," Statistical Science, vol. 21, no. 4, pp. 552-577, 2006.

[15] F. Lionetto and M. Frigione, "Environmental effects on the adhesion properties of nanostructured epoxy-silica hybrids," 
Journal of Applied Polymer Science, vol. 132, no. 36, Article ID 42514, 2015.

[16] "Polyethylene reference specimen for weathering test," JWTCS 4001, Japan Weathering Test Center, Tokyo, Japan, 2009.

[17] "Evaluating method of weathering conditions for plastics using polyethylene reference specimens," JWTCS 4002, Japan Weathering Test Center, Tokyo, Japan, 2009.

[18] Y. Takane, N. Kashino, and Y. Watanabe, "Availability of weathering reference materials for weatherability evaluation of polymeric materials," Journal of Structural and Construction Engineering, vol. 589, pp. 29-36, 2005.

[19] K. Ebe and N. Sekino, "Surface deterioration of wood plastic composites under outdoor exposure," Journal of Wood Science, vol. 61, no. 2, pp. 143-150, 2015.

[20] ISO, "Plastics-test specimens," ISO 20753, ISO, Geneva, Switzerland, 2008.

[21] ISO, "Plastics-determination of the melt mass-flow rate (MFR) and melt volume-flow rate (MVR) of thermoplastics-part 1: standard test method," ISO 1133-1, ISO, Geneva, Switzerland, 2011.

[22] "Plastics-differential scanning calorimetry (DSC)-part 3: determination of temperature and enthalpy of melting and crystallization," ISO 11357-3, ISO, Geneva, Switzerland, 2011.

[23] ISO, "Plastics-methods of exposure to laboratory light sources, part 2: xenon-arc lamp," ISO 4892-2, ISO, Geneva, Switzerland, 2013.

[24] ISO, "Plastics-methods of exposure to laboratory light sources, part 4: open-flame carbon-arc lamp," ISO 4892-4, ISO, Geneva, Switzerland, 2013.

[25] "Light-exposure and light-and-water-exposure apparatus (Enclosed carbon-arc type)," JIS B7751, JIS, Tokyo, Japan, 2007.

[26] ASTM, "Standard practice for enclosed carbon-arc exposure tests of paint and related coatings," ASTM D5031, ASTM International, West Conshohocken, Pa, USA, 2013.

[27] "Plastics-determination of flexural properties," ISO 178, ISO, Geneva, Switzerland, 2010.

[28] The Meteorological Agency, http://www.data.jma.go.jp/obd/ stats/etrn/index.php.

[29] K. Konno, T. Osaki, and S. Ide, "Carbonyl index for outdoor exposure tests in Japan," in Proceedings of the Materials Life Society 21st Research and Development Conference, pp. 63-64, 2010.

[30] D. Kusakabe and T. Kuriyama, "The factor analysis by the acceleration test on a carbonyl index profile of BPP moldings after outdoor exposure," in Proceedings of the Materials Life Society 21st Research and Development Conference Proceedings, pp. 59-60, 2010. 

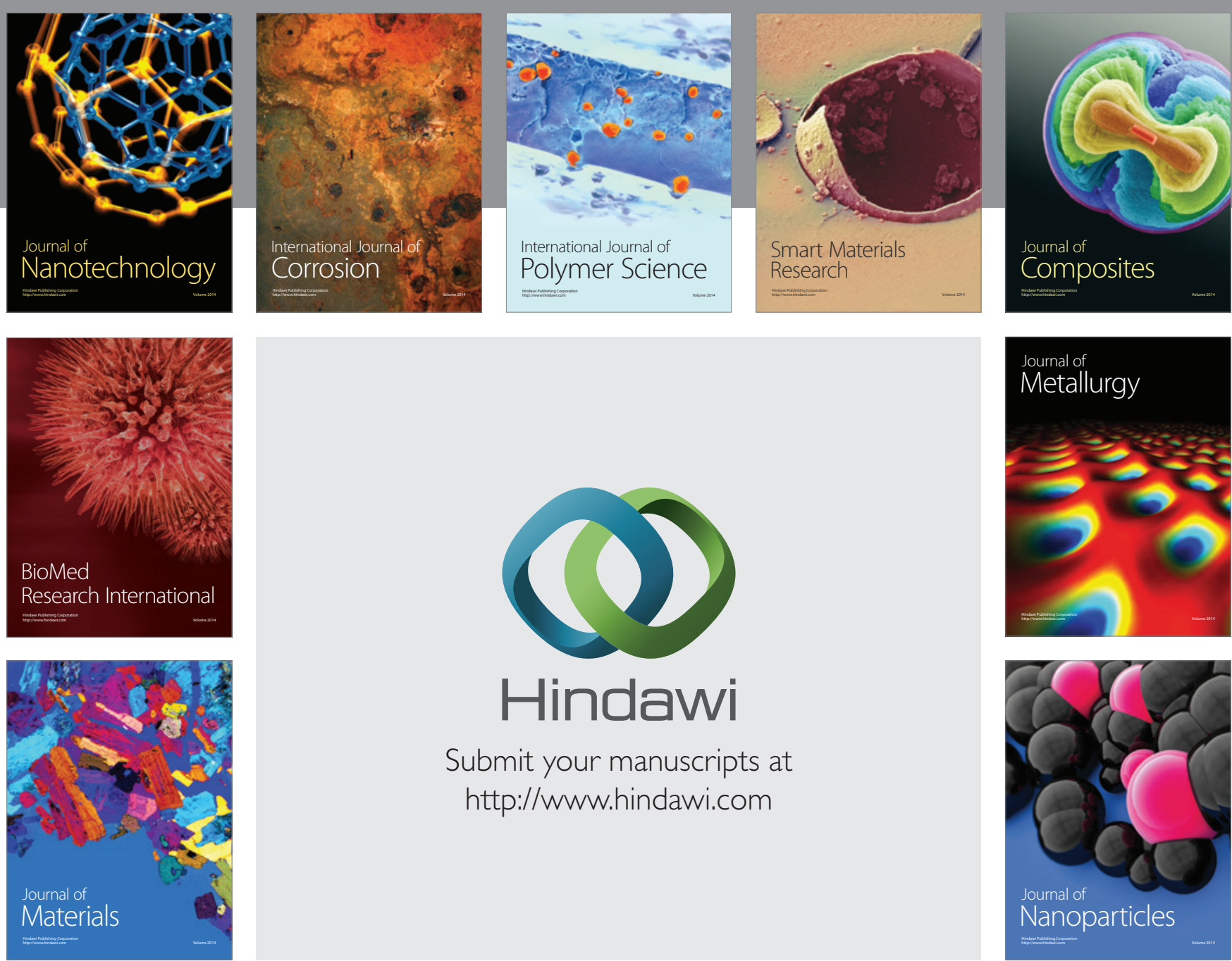

\section{Hindawi}

Submit your manuscripts at

http://www.hindawi.com

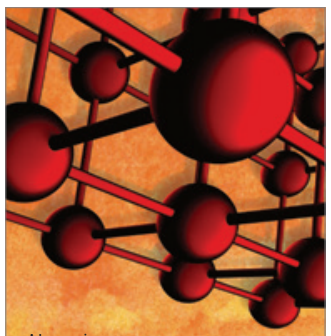

Materials Science and Engineering
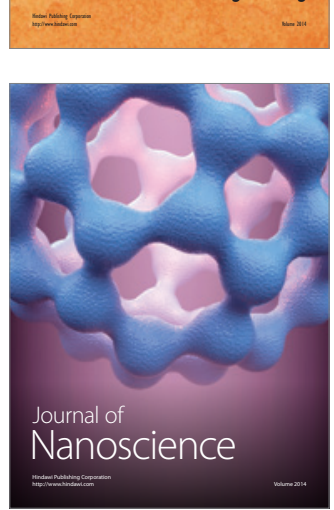
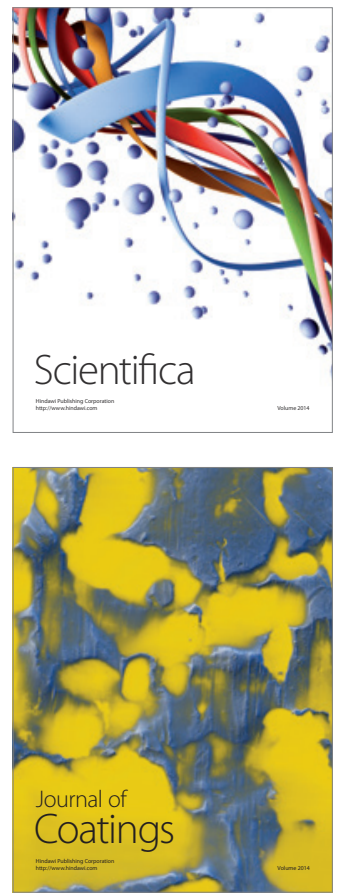
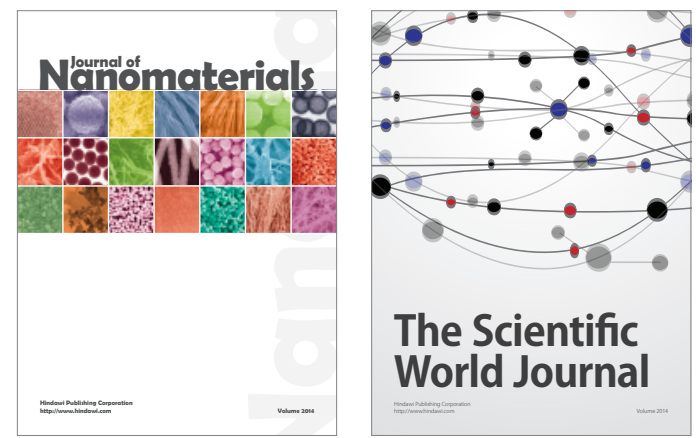

The Scientific World Journal
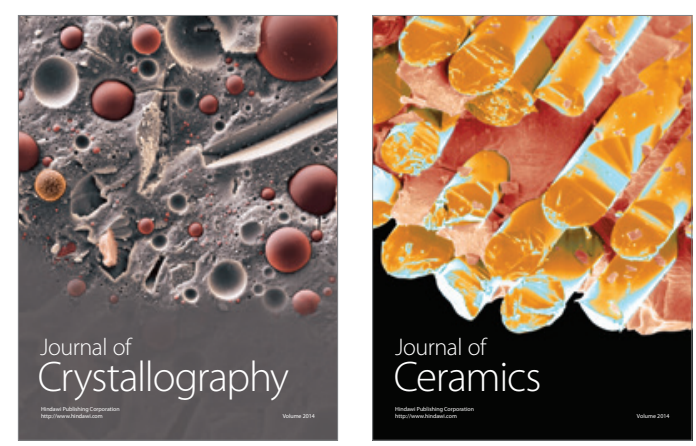
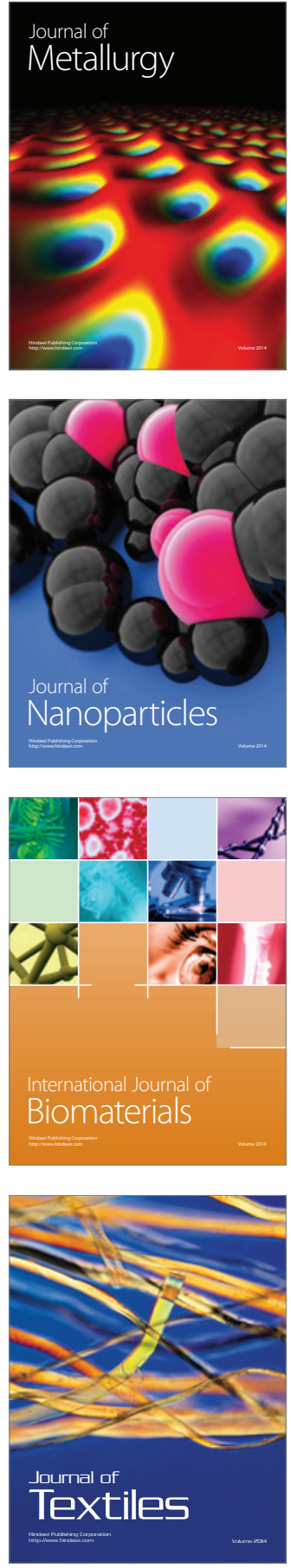